\title{
INICIAÇÃO À DOCÊNCIA: Importância da Construção de Saberes Relacionados à Prática Docente
}

\author{
Talita Molina Lopes Tanes ${ }^{1}$ \\ Elias Terra Werner ${ }^{2}$
}

\begin{abstract}
RESUMO
O objetivo deste estudo foi analisar os saberes docentes construídos no decorrer das atividades desenvolvidas por egressos do Programa Institucional de Bolsa de Iniciação à Docência (Pibid) no subprojeto "Pibid Biologia-Alegre" do Centro de Ciências Exatas, Naturais e da Saúde (CCENS) da Universidade Federal do Espírito Santo (Ufes). A pesquisa tem caráter qualitativo, caracterizada por um estudo de caso. O levantamento de dados foi realizado por meio de questionários e entrevistas semiestruturadas e as informações foram analisadas mediante análise de conteúdo, a partir de quatro categorias: saberes da formação profissional, saberes curriculares, saberes disciplinares e saberes experienciais. Os entrevistados relataram experiências formativas durante a participação no Pibid que possibilitaram a construção de saberes inerentes à prática docente e ressignificação de conceitos e aspectos relacionados ao saber-fazer docente, a partir da vivência em sala de aula. Ademais, a construção desses saberes possibilitou a compreensão de atividades que auxiliam a função, como o planejamento e organização; utilização de diferentes metodologias e recursos; conhecimento curricular e científico contextualizados e interação com alunos e demais sujeitos que compõem o ambiente escolar. Logo, conclui-se que o Pibid auxilia a prática docente, caracterizando-se como espaço formativo de construção e desenvolvimento de saberes docentes essenciais à profissão.
\end{abstract}

Palavras-chave: Pibid; saberes docentes; formação de professores; licenciatura.

\section{INITIATION TO TEACHING: IMPORTANCE OF BUILDING KNOWLEDGE RELATED TO TEACHING PRACTICE}

\section{ABSTRACT}

The objective of this study was to analyze the teaching knowledge built during the activities developed by alumni of the Institutional Scholarship Program for Initiation to Teaching (Pibid) in the subproject "Pibid Biologia-Alegre" of the Center for Exact, Natural and Health Sciences (CCENS) of the Federal University of Espírito Santo (UFES). The research has a qualitative character, characterized by a case study. The data collection was carried out through questionnaires and semi-structured interviews, and the information was analyzed through content analysis, from four categories: professional training knowledge, curricular knowledge, disciplinary knowledge and experiential knowledge. The respondents reported formative experiences during the participation in Pibid that enabled the construction of knowledge inherent to teaching practice and the redefinition of concepts and aspects related to teaching know-how, based on their experience in the classroom. Still, the construction of this knowledge made it possible to understand activities that help the function, such as planning and organization; use of different methodologies and resources; contextualized curricular and scientific knowledge and interaction with students and other subjects that make up the school environment. Therefore, it is concluded that the Pibid helps the teaching practice, characterizing itself as a formative space for the construction and development of essential teaching knowledge for the profession.

Keywords: Pibid; teaching knowledge; teacher training; graduation.

RECEBIDO EM: 31/8/2021

ACEITO EM: 4/11/2021

\footnotetext{
1 Autora correspondente. Universidade Federal do Espírito Santo (UFES). Centro de Ciências Exatas, Naturais e da Saúde (CCENS/UFES).Alto Universitário, Caixa Postal 16, s/n, Alegre/ES, Brasil. CEP 29500-000. http://lattes.cnpq.br/8040461410434610. https://orcid.org/00000001-7003-292X.talitatanes@gmail.com

2 Universidade Federal do Espírito Santo. Alegre/ES, Brasil. http://lattes.cnpq.br/3268068963656927. https://orcid.org/0000-0001-7781-4342
} 


\section{INTRODUÇÃO}

Uma das principais preocupações relacionadas à educação no século 21 é a busca pela valorização do professor (NÓVOA, 2009). A profissão docente, contudo, sempre esteve inserida em uma sociedade de constantes mudanças (como o surgimento de novas tecnologias e produção de novos conhecimentos), exigindo mais especialização dos professores, a fim de atender às novas demandas surgidas (NASCIMENTO; RODRIGUES, 2018). Logo, houve o aumento da busca pela melhoria da formação docente por meio da investigação de conhecimentos e saberes necessários para ensinar, com uma das estratégias sendo a criação de projetos voltados para a melhoria da profissão, aliada à ampliação dos saberes docentes (FREITAS, 2002).

Em contrapartida, os obstáculos relacionados à carreira docente, como o aumento da perspectiva produtivista; os desafios da gestão em sala de aula; as demandas da população e os problemas decorrentes das últimas crises econômicas, dificultam a profissão (FILHO; DIAS, 2016). Como consequência, a formação docente vem sendo pautada em dilemas e perspectivas que vão além da formação didático-pedagógica (SAVIANI, 2011).

A profissão docente é pouco atrativa no Brasil e, muitas vezes, os professores são expostos a situações de desvalorização, como péssimas condições de trabalho, carga horária excessiva, baixa remuneração e salários abaixo do piso salarial. Além disso, a ideia de que "ser professor é uma complementação de renda" contribui ainda mais para a desvalorização da carreira e o não reconhecimento da identidade profissional docente (CAVALCANTE; FARIAS, 2020).

Diante da baixa atratividade e desvalorização da profissão docente, a criação de programas de incentivo e valorização da carreira profissional tornou-se uma das estratégias adotadas por diversos países com o objetivo de valorizar a formação dos futuros professores. Esses programas têm obtido avaliações muito positivas, pois possibilitam uma formação de qualidade, reconhecem e se preocupam com a inserção dos professores recém-formados na carreira (GATTI, 2010).

No contexto brasileiro, destaca-se o Programa Institucional de Bolsa de Iniciação à Docência (Pibid) criado em 2007 pelo Ministério da Educação (MINISTÉRIO..., 2007), com o objetivo de inserir o futuro professor no ambiente escolar para que ele compreenda seu cotidiano e aprenda a lidar com outras situações além da sala de aula, desenvolvendo atividades inovadoras. Logo, a proposta é possibilitar uma formação inicial mais ampla e coerente com a profissão docente, uma vez que se torna mais evidente a correlação entre prática e teoria (NEITZEL; FERREIRA; COSTA, 2013). O Pibid surge como uma proposta de contribuir com o incentivo e a valorização da carreira docente, concedendo bolsas a alunos de Licenciaturas e aos demais participantes do Programa (MINISTÉRIO DA EDUCAÇÃO, 2007).

O Pibid proporciona a alunos na primeira metade do curso de Licenciatura uma aproximação prática com o cotidiano das escolas públicas de Educação Básica e com o contexto em que elas estão inseridas (CAPES, 2021). Entre os projetos e instituições contemplados pelo Pibid, encontra-se o foco deste estudo: o subprojeto "Pibid Biolo- 
gia-Alegre", do Centro de Ciências Exatas, Naturais e da Saúde (CCENS) da Universidade Federal do Espírito Santo (Ufes), localizado na região sul do Estado do Espírito Santo, no município de Alegre.

Com base nas informações levantadas sobre os obstáculos relacionados à atividade docente, vale ressaltar a importância das iniciativas e programas de incentivo e valorização docente para a formação de professores, pois possibilitam experiências significativas para a formação dos futuros professores dentro do âmbito escolar. Acredita-se, portanto, que as experiências vivenciadas no Pibid auxiliam na construção e desenvolvimento dos principais saberes docentes essenciais para a atuação profissional, aproximando os futuros professores do cotidiano escolar.

Logo, assumiu-se como eixo norteador desta pesquisa a seguinte questão: Quais saberes essenciais à prática docente podem ser construídos e desenvolvidos durante a participação nas atividades realizadas por egressos do Pibid? Com base nesse questionamento, o objetivo deste trabalho foi analisar os principais saberes docentes construídos no decorrer das atividades desenvolvidas por egressos do subprojeto "Pibid Biologia-Alegre". Acredita-se que os resultados apresentados por este estudo permitirão compreender e avaliar a contribuição do Pibid para a carreira docente e proporcionar a reflexão sobre sua importância para a formação de futuros professores por meio da inserção no contexto escolar ainda na formação inicial.

\section{SABERES INERENTES À PROFISSÃO DOCENTE}

O professor, no decorrer de sua prática, estabelece diferentes relações com os saberes construídos durante a sua história de vida, sua formação e o exercício da docência e, ao vivenciar as diversas situações em sala de aula, esses saberes passam a ser exigidos. O professor precisa conhecer o conteúdo que vai ensinar, definir objetivos a serem alcançados, selecionar metodologias e recursos que melhor se adéquem às atividades, elaborar instrumentos de avaliação e estabelecer uma relação saudável com seus alunos (CARMO, 2015).

Torna-se necessário o desenvolvimento de capacidades múltiplas pelo professor, além de virtudes e valores para que ele possa se aperfeiçoar permanentemente. 0 professor precisa ter a clareza de que ensinar está para além dos conteúdos, sendo fundamental o controle sobre suas ações e sobre o seu trabalho (MACENO; GUIMARÃES, 2014).

Para compreender os pressupostos que sustentam esses saberes, muitos autores têm estudado essa temática, destacando-se os trabalhos desenvolvidos por Gauthier (2013), Pimenta (2012), Saviani (1996), Shulman (1986) e Tardif (2012). Ao refletir sobre o objetivo desta pesquisa, encontrou-se nos trabalhos desenvolvidos por Tardif (2012) uma abordagem mais adequada para alcançá-lo. Tardif (2012, p. 255) define a epistemologia da prática docente, compreendendo "o conjunto dos saberes utilizados realmente pelos profissionais em seu espaço de trabalho cotidiano para desempenhar todas as tarefas". Trata-se do autor com maior presença no cenário nacional relacionado a essa temática e suas reflexões (especialmente sobre os saberes da experiência) têm sido pouco contestadas no campo educacional. 
Ao discorrer sobre o saber docente, Tardif $(2012$, p. 36) afirma que este é "[...] um saber plural, formado pelo amálgama, mais ou menos coerente, de saberes oriundos da formação profissional e de saberes curriculares, disciplinares e experienciais". Os saberes da formação profissional são os conhecimentos científicos e pedagógicos "transmitidos pelas instituições de formação de professores" durante a trajetória acadêmica inicial ou continuada e inseridos à prática docente (p. 36). Estes saberes se apresentam como

[...] doutrinas ou concepções provenientes de reflexões sobre a prática educativa no sentido amplo do termo, reflexões racionais e normativas que conduzem a sistemas mais ou menos coerentes de representação e de orientação da atividade educativa (TARDIF, 2012, p. 37).

Os saberes da formação profissional são divididos em dois eixos: o das ciências da educação e o da ideologia pedagógica. As ciências da educação vinculam-se, também, às Ciências Humanas, em que o foco de estudo é o professor e o ensino. Além de produzirem conhecimentos, as ciências da educação possuem o objetivo de incorporá-los à prática pedagógica mediante, principalmente, da formação inicial docente. Em contrapartida, a ideologia pedagógica ou saber pedagógico refere-se às teorias da aprendizagem e aos modos e técnicas de ensinar, englobando toda uma ideologia pedagógica (TARDIF, 2012).

Os saberes curriculares vão sendo construídos pelos professores ao longo do exercício da profissão e são aqueles originados por meio dos programas escolares (objetivos, conteúdos, métodos), apresentando-se nos Projetos Político-Pedagógicos das instituições escolares (TARDIF, 2012, p. 38). Por intermédio da prática e da socialização profissional no ambiente escolar, o professor passa a correlacionar a sua prática aos interesses e aspectos educacionais que a escola acredita, possibilitando a construção dos saberes curriculares.

Os saberes disciplinares correspondem às diferentes áreas do conhecimento (Física, Química, Biologia, Matemática, História, etc.) e são ensinados, basicamente, nas universidades e nas escolas, independentes das faculdades de educação e das áreas do campo da educação (TARDIF, 2012), e correspondem aos

[...] saberes de que se dispõe a nossa sociedade, tais como se encontram hoje integrados nas universidades, sob a forma de disciplinas, no interior de faculdades e de cursos distintos [...] e emergem da tradição cultural e dos grupos sociais produtores de saberes (TARDIF, 2012, p. 38).

Os saberes disciplinares são definidos e selecionados com o objetivo de discutir os diversos campos de conhecimento que "emergem da tradição cultural e dos grupos sociais produtores de saberes" (TARDIF, 2012, p. 38), os quais são organizados em forma de disciplinas. Nas escolas, no entanto, os conteúdos não são ensinados como são aprendidos nas universidades, posto que são ressignificados pelos professores no ato de ensiná-los. Essa ressignificação "deriva da ligação que se estabelece entre o conhecimento do conteúdo e a prática de ensino, o que significa que as discussões sobre o conteúdo devem ser relevantes ao processo de ensino" (TEXEIRA JÚNIOR, 2014, p. 26) e, consequentemente, ao estudante e ao professor. 
Os saberes experienciais são aqueles que se originam no cotidiano do trabalho docente e, de acordo com Tardif (2012, p. 39), são incorporados à experiência individual e coletiva sob a forma de habilidades de "saber-fazer" e de "saber-ser". São os saberes específicos de cada docente baseados no trabalho, no conhecimento e/ou relacionamento com outros profissionais que compõem a escola. Para o autor, os saberes experienciais referem-se a três dimensões:

a) as relações de interações que os professores estabelecem e desenvolvem com os demais atores no campo da prática; $b$ ) as diversas obrigações e normas às quais seu trabalho deve submeter-se; c) a instituição enquanto meio organizado e composto de funções diversas (TARDIF, 2012, p. 50).

Os saberes experienciais constroem-se no espaço da prática profissional, quando o professor (ou futuro professor) está inserido no ambiente escolar. Dessa forma, acredita-se ser possível iniciar o processo de construção desses saberes tanto a partir das próprias experiências docentes como também observando as experiências dos outros profissionais e demais indivíduos que compõem o ambiente escolar. De acordo com Carmo (2015), o professor é capaz de articular os saberes de forma tão sincronizada no cotidiano escolar que, muitas vezes, não é capaz de reconhecer onde termina um e inicia o outro.

\section{PERCURSO METODOLÓGICO}

Diante do objetivo proposto, quanto ao tipo de abordagem metodológica, optou-se pela abordagem qualitativa, classificada como um estudo de caso. A pesquisa foi realizada com cinco egressos do subprojeto "Pibid Biologia-Alegre" do CCENS/Ufes. Os critérios definidos para a escolha dos participantes foram: ser egresso(a) do subprojeto em questão e ter participado por, no mínimo, seis meses no subprojeto e atuar ou já ter atuado como professor(a) de qualquer instituição e nível de ensino durante o mesmo tempo mínimo, pois acredita-se ser o tempo necessário para que o participante tenha vivenciado experiências significativas em sua formação como bolsista do Pibid, além da experiência profissional mínima.

A coleta de dados deu-se em três etapas principais: obtenção das informações de contato de todos os egressos do subprojeto com a respectiva Coordenação de Área (60 egressos); o envio dos questionários para os egressos e a realização das entrevistas semiestruturadas. Os questionários foram enviados por meio de formulário on-line com 12 (doze) perguntas de respostas curtas visando à caracterização dos egressos quanto aos perfis acadêmico e profissional (Tabela 1 ).

Tabela 1 - Perguntas do formulário on-line

1. Informe o seu nome completo.

2. Informe o ano que você colou grau (Licenciatura em Ciências Biológicas) na Ufes. Caso ainda não seja formado(a), indique.

3. Por quanto tempo (em meses) você foi bolsista do Pibid?

4. Qual foi o motivo do seu desligamento no Pibid?

5. Você é ou já foi professor(a) após a conclusão da Licenciatura?

6. Caso seja ou já tenha sido professor(a), indique o tempo de serviço (em meses).

7. Em que nível de ensino você leciona ou já lecionou? 
8. Qualé sua condição atual ou de sua última atuação como professor(a)? (professor em designação temporária, contratado, efetivo, etc.).

9. Caso você seja convidado(a) para participar de uma entrevista que faça parte desta pesquisa, você aceitaria?

10. Caso a resposta acima seja não, indique o motivo.

11. Qual é a sua preferência para a realização da entrevista (videoconferência ou presencial)?

12. Qual é a sua preferência para que possamos manter contato para possível agendamento da entrevista e divulgação dos resultados da pesquisa?

Fonte: Os autores.

A fase de entrevistas foi realizada com cinco dos egressos que responderam ao questionário e apresentaram os critérios definidos para participação na pesquisa, sendo eles: participação mínima de 6 (seis) meses como bolsista do Pibid e como professor(a) após colação de grau. Os egressos que apresentam as características anteriormente descritas foram convidados para a etapa de entrevistas, totalizando cinco participantes que aceitaram ao convite. Todos optaram pela participação por meio de chamada por webconferências, gravadas mediante autorização, ocorridas nos meses de novembro e dezembro de 2019. A entrevista deu-se mediante o auxílio de um roteiro com perguntas previamente elaboradas acerca das experiências na formação inicial e participação no Pibid (Tabela 2).

Tabela 2 - Perguntas do roteiro de entrevista

1. Como foram os estágios supervisionados da licenciatura?

2. Como você avalia a relação entre teoria e prática vivenciadas no curso?

3. O que você esperava do Pibid ao se inscrever no programa?

4. Por que você optou por iniciação à docência e não pela iniciação científica?

5. Quais atividades que você desenvolveu no Pibid que foram mais significativas em sua formação inicial?

6. De maneira geral, como o Pibid contribuiu para a sua formação docente inicial?

7. Após o período como bolsista do Pibid, como ficaram suas concepções sobre a profissão docente?

8. Que avaliação você faz do Pibid?

9. Faça um panorama de sua atuação profissional docente (tempo de serviço, em quantas escolas já lecionou, públicas ou privadas, níveis de escolaridade...).

10. Atualmente, atua em quantas escolas, quantas turmas e em quais níveis de escolaridade?

11. No que diz respeito à docência e a sua participação no Pibid, faça a relação com:

- Aproximação com a realidade escolar.

- Convívio com colegas de profissão.

- Gestão em sala de aula e relacionamento com os alunos.

- Desenvolvimento de atividades e materiais pedagógicos diferenciados.

- Utilização de recursos facilitadores do ensino-aprendizagem (tecnologias, laboratórios, espaços não formais de ensino, logística, equipamentos, etc...).

- Conhecimentos de sua área de atuação.

- Planejamento e avaliação das aulas e da própria atuação docente.

- Contextualização da sua disciplina à realidade dos alunos;

12. Sua participação no Pibid influenciou na escolha de ser professor(a)?

13. Como o Pibid repercutiu ou está repercutindo em sua carreira docente?

14. Você teve de enfrentar algum desafio ou dificuldade no início da carreira docente? Se sim, quais e como foram superados? Como o Pibid contribuiu? Como imagina que seria caso não tivesse a experiência de ter sido bolsista do Pibid? 
Cabe ressaltar que a coleta de dados teve início somente após a aprovação do projeto desta pesquisa pelo Comitê de Ética em Pesquisas com Seres Humanos do Campus de Alegre da Ufes, a partir da divulgação do Parecer Consubstanciado que autorizou seu início, disponibilizado em junho de 2019 (CAAE: 12175619.6.0000.8151; Número do Parecer: 3.415.109).

Quanto à análise dos dados, as informações coletadas nos questionários foram organizadas no Microsoft Office Excel (Versão 2019), utilizando planilhas para compreensão e comparação das respostas, sendo possível traçar os perfis acadêmico e profissional dos participantes. Quanto às entrevistas, as informações narradas foram interpretadas por meio da Análise de Conteúdo (BARDIN, 2016), tendo como suporte teórico para a definição das categorias os estudos de Tardif (2012). Na Análise de Conteúdo o pesquisador busca a compreensão das características, estruturas ou modelos que estão implícitos em fragmentos de mensagens (GODOY, 1995).

Bardin (2016) descreve três fases fundamentais da análise de conteúdo: a pré-análise, a exploração do material e o tratamento dos resultados. A pré-análise é a fase de organização, ou seja, o estabelecimento de procedimentos bem definidos que irão orientar a interpretação. Na exploração do material, os dados são codificados, ou seja, transformados sistematicamente e reunidos em unidades. Na interpretação dos dados o pesquisador retorna ao referencial teórico, procurando embasar as análises. A relação entre as informações coletadas e a fundamentação teórica é o que norteia a interpretação (BARDIN, 2016).

O critério utilizado para a categorização foi semântico, ou seja, temas correspondentes à temática de saberes docentes e, a partir dos pressupostos teóricos e as classificações de saberes docentes à luz de Tardif (2012), foram selecionadas quatro categorias a priori: saberes da formação profissional; saberes disciplinares; saberes curriculares e saberes experienciais. Os trechos textuais narrados nas entrevistas que apresentaram evidências da construção de saberes docentes a partir das atividades desenvolvidas pelos egressos do subprojeto "Pibid Biologia-Alegre" foram agrupados em suas respectivas categorias, de acordo com a temática representada por cada uma e analisadas de acordo com o referencial teórico selecionado.

\section{RESULTADOS E DISCUSSÃO}

Foram contabilizados 60 (sessenta) egressos do subprojeto Pibid Biologia-Alegre e, destes, 27 (vinte e sete) responderam ao questionário, representando $45 \%$ de retorno. As informações coletadas nos questionários indicaram que o tempo médio de participação dos egressos no subprojeto foi de, aproximadamente, dois anos. Quanto à atuação profissional, 12 (doze) egressos (aproximadamente $45 \%$ dos 27 que responderam ao questionário) indicaram que atuam ou já atuaram como professores do ensino básico sendo, aproximadamente, 59\% na rede pública de ensino contra $41 \%$ na rede privada.

Quanto à etapa de entrevistas, dos 12 egressos mencionados anteriormente, 6 apresentaram os critérios de participação mínima de seis meses no Pibid e de atuação profissional, definidos para seleção dos sujeitos da pesquisa, sendo estes os convidados 
para tal etapa (aqui denominados Egressos 8, 12, 19, 25, 26 e 27). Somente o Egresso 27 não retornou o convite, logo, os egressos do subprojeto "Pibid Biologia-Alegre" que foram entrevistados foram os Egressos 8, 12, 19, 25 e 26.

Com o objetivo de analisar a construção dos saberes docentes a partir das experiências vivenciadas no Pibid e a contribuição de cada conjunto separadamente, estes serão organizados adiante, respectivamente, nas quatro categorias de saberes docentes descritos por Tardif (2012), a fim de análise, embora vale ressaltar que eles são complementares, articulados e atuem juntos por uma proposta de reflexão sobre a temática.

\section{Saberes da Formação Profissional}

Ao frequentar o ambiente escolar por meio das atividades proporcionadas pelo Pibid, os futuros professores apontaram a confrontação entre a teoria estudada durante a formação inicial e a prática docente, sendo habilitados a refletirem sobre a ressignificação da concepção da carreira docente, como indicado em alguns trechos das entrevistas:

Após o período do Pibid, percebi que a carreira docente é como qualquer outra carreira com as suas dificuldades, mas acho que quando a gente ouve falar que ser professor é por amor, esse discurso acaba inviabilizando a profissão, trazendo a profissão para outro patamar, como se para ser professor, a gente não precisasse ter toda a formação que temos durante a licenciatura (EGRESSO 19).

O que a gente vê muito hoje em dia são pessoas que acreditam que para ser professor, qualquer pessoa pode, é só chegar na sala de aula, repetir o conteúdo que está no livro e não é bem assim. Quando eu saí da escola (enquanto docente) e entrei no Pibid, eu realmente vi, meu Deus, que eu era péssima professora, que eu era muito conteudista, batia na tecla do conteúdo [...] e a experiência do Pibid me fez ter outra visão enquanto sala de aula, me fez colocar mais o pé no chão e ter uma visão mais holística da profissão (EGRESSO 25).

O Pibid mostra a realidade da sala de aula e não é igual aquele sonho que você tem da profissão, sabe? O Pibid mostrou que, apesar de todas as dificuldades, a gente não pode se acomodar, mesmo que o sistema seja difícil, a gente sempre tem que buscar novas coisas para sua aula valer a pena (EGRESSO 26.).

O Egresso 25 relatou a experiência de ter sido professor durante sua formação inicial, antes da participação no Pibid e, ao relembrar sua atuação como docente, afirmou que adotava uma postura conteudista. Tal reflexão deu-se a partir das experiências vivenciadas no Pibid, possibilitando a ressignificação da carreira docente. Observa-se, dessa maneira, que o contato frequente com o ambiente escolar possibilita a construção de saberes da formação profissional, pois os futuros professores passam a confrontar os conhecimentos das ciências da educação com a realidade escolar, como ocorrido com o Egresso 25 que, ao comparar sua atuação docente antes e depois da participação no Pibid, teve a possibilidade de ressignificar a própria prática.

De acordo com Tardif (2012), a carreira docente exige a compreensão das ciências da educação e a articulação lógica dos diferentes saberes na prática. A prática docente estimula a construção dos saberes pedagógicos, que se apresentam como "[...] doutrinas ou concepções provenientes de reflexões sobre a prática educativa no sentido 
amplo do termo" (TARDIF, 2012, p. 37). De acordo com Carmo (2015), a prática docente não se efetiva sem se relacionar com o arcabouço teórico proveniente do campo das ciências da educação. Assim sendo, quando o futuro professor constrói um vínculo efetivo de formação com o ambiente escolar, ele compreende a importância desse arcabouço teórico.

O Egresso 19 relatou que, durante sua participação no Pibid, no contato com a escola, passou a compreender a existência de dificuldades na profissão docente, bem como o Egresso 26, que afirmou que a profissão docente não é como o "sonho" que ele tinha, ou seja, ambos os entrevistados ressignificaram as suas concepções sobre a função docente ao participar do Pibid. Para Pimenta (2012), quando ingressam no curso de formação inicial, os alunos já chegam com saberes sobre o que é ser professor, no entanto o maior desafio na formação inicial é o processo de transição dos alunos de seu "ver o professor como aluno ao seu ver-se como professor" (p. 21), ou seja, o processo de construção da identidade docente. Nessa perspectiva, os trechos das falas anteriores indicam que o Pibid é fundamental nesse processo, pois possibilita que os futuros professores construam a própria identidade docente.

De acordo com Tardif (2012, p. 37), os conhecimentos pedagógicos fornecem, de um lado, "[...] o arcabouço teórico ideológico à profissão" e, de outro, procedimentos mais técnicos, relacionados ao "saber-fazer" por exemplo, o planejamento das aulas, que permite que o professor se organize quanto às atividades desenvolvidas. Nas falas dos entrevistados foram encontrados indícios da construção desses saberes relacionados ao fazer docente, como apresentados a seguir:

Eu acredito que as atividades de planejamento das aulas do Pibid foram essenciais na minha formação como futura professora de Ciências, contribuíram de forma substancial (EGRESSO 12).

Todos os alunos que passaram pelo Pibid, quando futuramente forem se deparar com uma sala de aula e precisarem planejar um experimento, uma aula prática, alguma atividade lúdica diferente, não vão ter a mesma dificuldade do professor que não passou por essa experiência (EGRESSO 25).

O Pibid me ajudou muito na questão no planejamento e principalmente no tipo de atividade que eu poderia utilizar para dar aula em diferentes turmas (EGRESSO 26).

O conhecimento teórico relacionado às ciências da educação, construído na formação inicial, teve significado para os entrevistados a partir do momento em que se depararam com a necessidade de colocar em prática o planejamento das atividades que seriam desenvolvidas em sala de aula, ainda na condição de bolsistas do Pibid, refletindo na própria atuação como docentes. Destaca-se, novamente, a importância do Pibid para que o futuro professor possa fazer a relação entre a teoria das ciências da educação com a própria prática no ambiente escolar, indicando que no decorrer das atividades do Pibid existe a busca pela integração da prática com a teoria.

Nesse sentido, ao realizar a análise das entrevistas sob a perspectiva de construção de saberes pedagógicos, observa-se que, ao fazer a relação entre as ciências da educação presentes nos cursos de Licenciatura e as atividades realizadas no Pibid, aos futuros professores possibilita-se uma formação que garanta subsídios necessários para 
a preparação para a carreira docente, estando de acordo com a realidade do ambiente escolar e buscando caminhos que possam reduzir as dificuldades que poderão surgir na profissão.

\section{Saberes Curriculares}

Ao realizar a análise das entrevistas foi observado que as experiências proporcionadas pelo Pibid permitiram aos entrevistados a compreensão e reflexão sobre diferentes possibilidades de currículos escolares. 0 Egresso 8, por exemplo, durante a sua participação no Pibid, vivenciou duas possibilidades curriculares: durante um período, atuou em uma escola de Ensino Fundamental e, em outro período, lecionou em uma escola de Ensino Médio. A partir das experiências distintas, ocorreram mudanças na proposta curricular que foram indicadas pelo entrevistado e que refletiram em sua carreira docente:

O conhecimento do Pibid a gente leva para a vida toda [...] A forma com que a gente abordava determinados assuntos tanto no ano que eu trabalhei com ensino médio quanto o outro ano que eu trabalhei com o ensino fundamental era diferente, apesar de serem os mesmos assuntos [...] e eu trazia isso para as minhas aulas porque eu via depois daquelas avaliações que a gente fazia no relatório mensal do Pibid, que de fato dava certo, então as atividades do Pibid que davam certo eu levava para as minhas salas de aula e também via resultado (EGRESSO 8).

A mudança de nível de ensino durante a participação do Egresso 8 no Pibid, proporcionou-lhe a compreensão de que um mesmo conteúdo curricular pode ser ensinado de diferentes formas, a depender do nível de ensino trabalhado. Além disso, as atividades diferenciadas elaboradas pelo egresso quando era bolsista, puderam ser utilizadas em suas próprias aulas como docente, indicando a importância que as atividades do Pibid têm na sua profissão, pois além de proporcionarem a reflexão e construção dos saberes curriculares, auxiliam na criatividade de suas aulas.

$O$ relato do Egresso 8 também enfatiza outros aspectos importantes que o Pibid proporciona para a formação inicial, como a autoavaliação em relação à prática docente e o desenvolvimento das atividades em sala de aula, por meio da construção de um relatório mensal que egressos do Pibid-Biologia Alegre do CCENS/Ufes elaboravam ao final de cada mês acerca das atividades desenvolvidas durante aquele período de tempo. As informações do relatório mensal acerca das atividades desenvolvidas na escola são construídas de forma colaborativa (bolsistas e professor da educação básica) a partir das experiências compartilhadas somadas ao conhecimento teórico-pedagógico construído durante a formação inicial, proporcionando uma reflexão sobre como se revela importante, por exemplo, o processo de planejamento, desenvolvimento, aplicação e avaliação que compreende a ação docente, entre outras experiências que são compartiIhadas conforme as atividades são desenvolvidas em sala de aula.

Como consequência, o Egresso 8 passa a compreender que o professor pode relacionar as questões cotidianas de seus alunos com o conteúdo que ele está ensinando, ainda que seja necessário seguir um livro didático, pois o professor tem a autonomia de propor como ensinará determinado assunto a partir do contexto e da necessidade de 
sua turma, ou seja, conforme defendido por Martins (2013), o futuro professor compreende-se como um mediador entre o conhecimento que foi historicamente produzido e aqueles indicados no currículo, com o objetivo de torná-los relevantes para a turma.

Ao ser desenvolvido na escola, o currículo também deve despertar a construção do conhecimento científico e a formação do indivíduo como cidadão social e cultural, ou seja, o currículo não deve ter embasamento somente no conteúdo teórico, mas possibilitar a formação mais ampla dos alunos (RIBEIRO, 1993). Nessa perspectiva, os entrevistados relataram, em algumas de suas falas, que as atividades do Pibid possibilitaram a elaboração de atividades que permitem essa formação mais ampla:

O que eu mais fiz no Pibid foi propor novas atividades, então eu consegui ver a diferença no processo de construção do conhecimento dos alunos e eu tento até hoje, como professora, trazer algo diferente, que chame atenção deles, porque só a teoria ou só o livro didático, você não consegue chamar a atenção do aluno, então você vai lá e faz uma prática ou então um jogo, aí o aluno consegue ter essa percepção totalmente diferente do conteúdo e eu acho que isso foi mais significativo para mim, eu consegui entender esse processo de construção do conhecimento (EGRESSO 12).

Nas minhas aulas, sempre estou levando meus alunos para alguma coisa fora do espaço formal de ensino, e eu sempre busco na memória as coisas que eu vivi e aprendi no Pibid, pois ele me mostrou diferentes estratégias. O Pibid mostrou que eu tenho outros recursos para utilizar e principalmente materiais que você nunca imagina que pode usar e que no final acaba te auxiliando... Então o Pibid te fornece instrumentos essenciais para conseguirmos dar aula (EGRESSO 25).

Pode-se observar, nos trechos supramencionados, a construção de saberes relacionados ao currículo, pois os entrevistados relataram que, por meio das atividades vivenciadas no Pibid, desenvolveram a prática de elaborar diferentes formas de ensinar, uma vez que esses egressos relataram que toda semana eles buscavam desenvolver, mediante pesquisas e auxílio dos materiais didáticos que o Pibid proporcionava (kits de laboratório, modelos de representações das células e outras estruturas biológicas, kits de materiais de papelaria, entre outros), atividades que fossem diferentes da aula expositiva tradicional, como aulas fora da sala de aula ou com a utilização desses materiais disponíveis para o desenvolvimento das atividades. Além disso, a partir dessas possibilidades diferenciadas, os bolsistas compreendem que a atividade docente não se restringe somente ao livro didático e apresentações no Power Point, proporcionando essa reflexão sobre as diferentes formas de se ensinar os diferentes conteúdos curriculares em diferentes turmas e em como adequar as atividades de acordo com esses aspectos, com o intuito de um determinado conteúdo ser mais interessante para os seus alunos e, consequentemente, uma aula mais motivadora.

Segundo Amaral et al. (2013), o professor dos dias atuais tem o desafio de descobrir novos caminhos e recursos que reestruturem o ensino, e isso implica reorganizar e repensar os conteúdos no contexto escolar, possibilitando a articulação de um currículo que potencialize outros aspectos essenciais ao desenvolvimento do indivíduo, permitindo que o aluno reconheça a sociedade em que está inserido por meio dos conteúdos científicos, mas que também seja formado culturalmente. 
Dessa forma, vale ressaltar a importância da integração entre universidade e escola durante a formação docente inicial, pois permite que os futuros professores discutam e reflitam sobre os currículos vigentes na escola, articulando-os aos conhecimentos educacionais e reestruturando-os para alcançarem um ensino socialmente relevante (CARMO, 2015).

O currículo é uma possibilidade que a escola tem para organizar os conhecimentos, mas a articulação em sala de aula pode ser flexível, visto que "para alcançar fins pedagógicos, o professor também se baseia em juízos ligados a tradições escolares, pedagógicas e profissionais que ele mesmo assimilou e internalizou" (TARDIF, 2012, p. 211). Essa flexibilização possibilita que o docente busque outros recursos e métodos diferentes do livro didático, por exemplo, para que suas aulas se tornem mais atrativas e interessantes, cumprindo, dessa forma, com sua função como profissional docente.

Vale ressaltar a importância que as atividades do Pibid têm ao proporcionar aos futuros professores o acesso a um conjunto de estratégias de ensino, como a possibilidade de desenvolver atividades com o auxílio de materiais didáticos disponibilizados para os alunos do Pibid, além do auxílio dos próprios professores da universidade e demais iniciativas que os bolsistas buscam para possibilitar aulas mais dinâmicas e inovadoras (estratégias que nem sempre são possíveis de serem aplicadas em um contexto de escola pública de educação básica), auxiliando-os no exercício da profissão docente a partir de novas possibilidades. Dessa forma, serão capazes de reconhecer que o ensino não é restrito aos conhecimentos científicos, mas deve proporcionar aos alunos o interesse pelo conhecimento. Ao vivenciar o Pibid, o futuro professor tem a possibilidade de compreender que a estrutura curricular da escola nem sempre é suficiente no processo social e cultural dos alunos e que as escolas precisam valorizar a criatividade tanto dos professores quanto dos próprios alunos.

Dessa forma, é possível indicar que a participação no Pibid permite que os futuros professores compreendam, a partir das atividades vivenciadas, a existência de diferentes formas de organizar o currículo escolar, interferindo diretamente no processo de ensino e aprendizagem, ou seja, o Pibid possibilita reflexões sobre o currículo escolar que poderão auxiliar na atividade docente dos futuros professores que vivenciam esse momento dentro da formação inicial. De acordo com Carmo (2015), as experiências relacionadas ao currículo escolar, no contexto do Pibid, também possibilitam uma visão crítica de organização curricular e dos conteúdos, atendendo às expectativas das escolas, sem que se distanciem do que o docente julga ser importante no processo de formação de seus alunos.

\section{Saberes Disciplinares}

Por meio da experiência de vivenciar as atividades do Pibid, o futuro professor passa a compreender, por exemplo, a diferença entre as disciplinas cursadas na universidade daquelas que serão ministradas na escola para os alunos do ensino básico, como observado nas falas dos Egressos 8 e 12: 
Acho que o principal desafio de um professor é fazer com que uma turma totalmente heterogênea consiga assimilar de fato o que você quer passar, por exemplo, alguns conteúdos como Genética, Física e Química para o 9o ano são muito difíceis até para a gente na graduação, quanto mais para os meninos (alunos) e o Pibid me ajudou a superar isso (EGRESSO 8).

Eu acho que o Pibid trouxe a questão do refinamento do conhecimento, pois a gente aprende na faculdade algo muito superior e a gente tem que começar a diminuir o tom, falar com menos palavras técnicas às vezes, uma forma de conseguir alcançar os alunos, pois tem palavras que eles não entendem (EGRESSO 12).

A oportunidade de vivenciar a sala de aula, proporcionada pelas atividades do Pibid, permite que o futuro professor inicie o processo de ressignificação dos conteúdos científicos das disciplinas específicas do curso de formação inicial, compreendendo as diferenças existentes entre essas disciplinas e aquelas que terá de ensinar em sala de aula para alunos do ensino básico, como relatado nos trechos anteriores. Pode-se afirmar, dessa forma, que a participação no Pibid os auxiliou nesse processo, pois ao vivenciar o espaço escolar, os futuros professores buscaram alternativas diversas para aproximar o conteúdo sistematizado aos conhecimentos dos seus alunos, possibilitando a compreensão e ampliando, assim, as possibilidades de construção do conhecimento pelos alunos.

Alguns autores, como Carvalho e Gil Pérez (2001) e Bizzo (2002) questionam o currículo com intuito de romper com a perspectiva de ensino baseado na memorização, pensando a partir da contextualização e discussão dos conhecimentos científicos, para que estes façam sentido aos alunos. Alguns trechos das falas dos entrevistados indicam que as experiências vivenciadas no contexto do Pibid possibilitaram a construção de saberes disciplinares relacionados à contextualização, como apresentado a seguir:

Eu acho que o Pibid me ajudou principalmente quando fui trabalhar com alunos de escola de periferia, na qual eu atendia muitos meninos do interior e foi bem importante porque eu me preocupei em voltar o conteúdo para a realidade deles, para o aprendizado, para algo que fosse bom para a vida deles (EGRESSO 12).

O Pibid como um todo foi excelente com relação à contextualização, à realidade dos alunos. Eu acho que quando o aluno vivencia a prática daquele conteúdo que está aprendendo, de fato ele percebe que é importante. É importante todo esse aporte teórico da Educação, mas o professor precisa contextualizar, não adianta ir para a sala de aula achando que o que funcionou para mim vai funcionar para os alunos, nós estamos em outros tempos, nós temos uma diversidade muito grande de alunos nas escolas, a gente precisa estar preparado para isso (EGRESSO 25).

Dessa forma, pode-se afirmar que o Pibid possibilita que os futuros professores façam a reestruturação das disciplinas e conteúdos que irão ministrar em sala de aula, auxiliando-os na prática, visto que o contato frequente com alunos de Educação Básica de diferentes contextos, proporcionado pelas atividades desenvolvidas no Programa, possibilita que os futuros professores compreendam, na prática, a importância de adaptar os conteúdos curriculares à realidade de cada turma. Além disso, esse contato frequente com o ambiente escolar possibilita um conjunto de reflexões sobre como a escola e a sociedade estão envolvidas com a divulgação do conhecimento científico, pensando na função social da escola (CARMO, 2015). No momento em que as pessoas 
estabelecem interações entre elas por meio do conhecimento, elas proporcionam o melhor convívio social e desenvolvimento cidadão (CORREIA, 2012), ou seja, os futuros professores podem avaliar os saberes disciplinares para, em conjunto com os alunos da Educação Básica, professores e comunidade, estejam aptos a alcançar o principal objetivo da função docente, que é a construção do conhecimento.

A partir da análise das entrevistas, portanto, foi observado que os egressos do $\mathrm{Pi}$ bid, ao vivenciarem o espaço escolar, ressignificaram os saberes específicos construídos na universidade, permitindo a reflexão e a compreensão das características das disciplinas dentro do contexto escolar, buscando atividades que sejam adequadas às suas turmas.

\section{Saberes Experienciais}

Ao analisar as narrativas realizadas pelos entrevistados, foi observado que o Egresso 25 relatou a importância de vivenciar a realidade escolar para entender as suas características e particularidades, não mais como aluno, mas como profissional daquele ambiente:

$\mathrm{O}$ aluno que passa pelo Pibid se depara de fato com a realidade da escola em si. Ele entende como se organizam as funções dentro da escola e a importância de cada uma delas. A gente assume a responsabilidade mesmo, apesar do programa não ser pra gente assumir $100 \%$ a responsabilidade da sala de aula, mas em alguns casos a gente sabe que o aluno acaba assumindo sim essa responsabilidade e por um lado eu vejo como positivo isso acontecer ainda na Licenciatura. Então realmente 0 aluno aprende a como ser um professor tendo a vivência de como ser um professor no próprio espaço em que o professor atua (EGRESSO 25).

Quando os bolsistas do Pibid vivenciam a escola como futuros professores, começam a compreender a realidade do espaço escolar como futuro local de trabalho e a sua organização, entendendo que "[...] a escola possui algumas características organizacionais e sociais que influenciam o trabalho dos agentes escolares" (TARDIF, LESSARD, 2014, p. 55), ou seja, passam a compreender não só a tarefa docente, mas todas as funções relacionadas ao espaço escolar. Os futuros professores deparam-se com a estrutura e o planejamento escolar, entendendo que a ação do professor não é restrita somente à sala de aula. Dessa forma, tem-se a compreensão da escola como local de trabalho e, também "[...] espaço social que define como o trabalho dos professores é, como é planejado, supervisionado, [...] e visto pelos outros" (TARDIF, LESSARD, 2014, p. 55), e não apenas um espaço físico.

O contato frequente que o futuro professor tem com o espaço escolar, ainda na formação inicial, proporcionada pelas atividades do Pibid, contribui para que não ocorra o que podemos denominar de "choque" de realidade. Desde a formação inicial, o futuro professor compreende que o docente não atua na escola de maneira isolada, focando-se apenas na sala de aula e no conteúdo a ser ensinado, mas compreende a ação docente por uma perspectiva social na interação com os indivíduos que compõem o espaço escolar (CARMO, 2015). Alguns entrevistados relataram que a participação no Pibid os auxiliou no início de suas carreiras como docentes: 
Eu posso afirmar que o Pibid fez com que eu entrasse dentro de uma sala de aula para ministrar uma atividade de forma segura, pois eu já havia tido contato anteriormente com alunos tanto em aulas práticas, teóricas e aulas de campo (EGRESSO 8).

O Pibid me ajudou muito e foi bom porque quando saí da Licenciatura e fui para a sala de aula como professora, eu não levei aquele susto. O Pibid foi fundamental para eu poder perder o medo da sala de aula (EGRESSO 12).

Nossa! O Pibid é excepcional porque eu acho que ele que dá segurança quando saímos da universidade para poder começar a carreira docente, então eu o acho extremamente importante (EGRESSO 26).

O "susto" mencionado pelo Egresso 12 refere-se justamente ao "choque" de realidade, ou seja, o primeiro contato com a escola após a conclusão do curso de formação inicial, que pôde ser minimizado por meio da experiência do Pibid, preparando-o para o início da carreira docente, bem como mencionam os Egressos 8 e 26, ao relatarem que a participação no Pibid trouxe-Ihes segurança para começarem a trajetória como profissionais, ressaltando mais uma vez a importância do Pibid na construção de saberes relacionados à experiência docente.

O ambiente escolar, apesar de possuir sua própria organização, também reserva algumas situações que podem interferir diretamente na prática docente, dificultando o planejamento do professor, exigindo dele alternativas distintas imediatas. O Egresso 25 relata, em uma de suas falas, a importância do Pibid na ocorrência de situações não previstas que podem surgir no espaço escolar:

No Pibid a gente aprende o que fazer quando nos deparamos com situações não previstas, como organizar as turmas que são totalmente diferentes umas das outras em determinadas atividades [...] Com o convívio com os colegas de profissão, por exemplo, a gente consegue perceber quais deles estão ali para ajudar com essas dificuldades que aparecem e isso eu aprendi através da participação em grupo que a gente tem no Pibid e acho que isso fortalece a profissão, o companheirismo[...] (EGRESSO 25).

$\mathrm{O}$ relato anterior indica que as atividades do Pibid e o contato frequente com o espaço escolar e auxílio dos "colegas de profissão" (nesse caso, compreende ao grupo de bolsistas do Pibid do mesmo subprojeto que atuam nas mesmas escolas de Educação Básica e elaboram as atividades em conjunto) preparam o futuro professor para o enfrentamento de forma colaborativa de situações que são inesperadas em sala de aula. Chapani e Luz (2018, p. 13) enfatizam que essa possibilidade apresentada pelo Pibid em reunir diferentes profissionais em distintos contextos (licenciandos, professores da Educação Básica, professores universitários) "para discutir, interpretar e apontar alternativas para as questões que emergem da compreensão da escola e da reflexão sobre a prática é um dos aspectos mais inovadores do programa", o que contribui para o preparo e formação desses futuros profissionais que participam das atividades proporcionadas pelo Pibid.

O Egresso 25 menciona a dificuldade em organizar turmas distintas em uma determinada atividade que seria, em princípio, igual nas duas turmas. Como relatado, no entanto, o fato de serem turmas distintas não era esperado naquela ocasião, o que o exigiu a reorganização das turmas (ou poderia ser até mesmo da própria atividade) para 
que fosse possível a realização da atividade planejada. Tais situações despertam no docente a capacidade de reorganização e "exigem do professor improvisação e habilidade pessoal, bem como a capacidade de enfrentar situações mais ou menos transitórias e variáveis" (TARDIF, 2012, p. 49). O futuro professor, portanto, em contato frequente com a escola e outros profissionais, no contexto do Pibid, tem a possibilidade de construir saberes experienciais relacionados à função docente, sendo por ela mobilizado e modelado, construindo experiências e dando importância para o papel do profissional docente (TARDIF, 2012).

Essa dinâmica de ações colaborativas que possibilita a construção de saberes experienciais concretiza-se na prática, ao longo da vida profissional. Logo, esse conjunto de saberes se constrói e reconstrói durante o período de participação no Pibid, pois por meio dele o futuro professor permanece em contato com a rotina profissional antes de sua entrada definitiva na carreira (ROSA; MENDES; LOCATELLI, 2018).

Além das experiências relatadas nos trechos anteriores, os entrevistados também indicaram o início da construção de saberes ligados à relação entre professor e aluno. Em suas narrativas, eles reconheceram a importância do Pibid na relação com os seus alunos nos dias atuais.

Eu não consigo imaginar como seria sem o Pibid porque ele fez parte da minha formação e contribuiu até mesmo com meu posicionamento como professor, como lidar com o aluno, o que eu via que dava certo ou não, [...] ao mesmo tempo eu também aprendi durante o Pibid o que eu não poderia fazer dentro de uma sala de aula, por exemplo, a forma como lidar com alguns alunos que possuem dificuldades de comportamento ou de concentração (EGRESSO 8).

Hoje como professora eu consigo me relacionar muito bem com os meus alunos, ser amiga deles... Eu devo isso à época do Pibid, que eu via essa relação mais amigável entre professor e alunos (EGRESSO 19).

A minha posição como professora, o meu relacionamento com os alunos hoje, estão muito melhores devido a minha participação no Pibid, o que eu passei dentro das escolas com o Pibid (EGRESSO 26).

Ao analisar as narrativas anteriores, pode-se afirmar que, ao participar do Pibid, os futuros professores iniciam o processo de construção do saber de interação que, segundo Baccon e Arruda (2010, p. 520), "refere-se ao saber relacionar-se com o aluno e sustentar essa relação, saber gerenciar as relações subjetivas na sala de aula, intervindo apropriadamente no momento da ação". A interação é essencial para o desenvolvimento da prática docente, pois permite que o professor conheça os seus alunos e, quando em contato com eles em sala de aula, pode compreender os conhecimentos que eles têm, bem como o contexto de vida deles, criando "subsídios para seu trabalho em sala de aula, uma vez que esse mundo irá influenciar sobremaneira o modo como os alunos construirão os conteúdos escolares" (BELOTTI; FARIA, 2010, p. 7).

Outro saber construído por meio das atividades do Pibid referido à experiência e indicado por um dos entrevistados foi a organização em sala de aula relacionada à duração do tempo das aulas: 
O Pibid me trouxe uma boa base, principalmente com o tempo (duração da aula), se a minha aula estava grande, se estava pequena, acho que nisso o Pibid me ajudou muito, porque eu aprendi a me planejar melhor e me organizar caso uma aula que eu montei acabasse antes do tempo previsto, aí eu sempre levava algo extra, ou se ela não acabasse naquele tempo que eu calculei, eu teria que replanejar outra aula mais para frente para poder caber no período letivo [...] (EGRESSO 26).

O trecho indica que o Egresso 26, ao participar das atividades na escola na condição de bolsista do Pibid, compreendeu a importância de planejar suas aulas de acordo com a duração (minutos) para, em caso de necessidade, reestruturá-las. A distribuição do tempo é muito importante para a prática do professor e saber administrá-lo torna-se possível a partir da própria experiência em sala de aula, como o contato frequente que os alunos do Pibid têm no espaço escolar. Segundo Carmo (2015), refletir sobre a duração da aula faz-se necessário para que as atividades tenham sentido e significado para os alunos.

Dessa forma, pode-se afirmar que a experiência proporcionada pelo Programa de possibilitar aos futuros professores esse contato com o ambiente escolar antes de atuarem profissionalmente de forma efetiva, é um de seus principais (se não o principal) diferenciais, pois permite que esses futuros profissionais tenham conhecimento das mais importantes atribuições que um professor precisa para atuar profissionalmente, sem precisar passar pelo "choque" de realidade, como mencionado anteriormente. Tal aspecto está presente, por exemplo, na pesquisa realizada por Chapani e Luz (2018, p. 10) que, ao questionarem os egressos de um subprojeto do Pibid sobre sua principal contribuição para a formação docente, estes indicaram "a oportunidade de interação com a futura profissão", mencionando a expressão "vivência prévia" com os alunos e o ambiente escolar, o que vai ao encontro do principal objetivo do Pibid, que é a aproximação do futuro professor do ambiente escolar.

A relação existente entre os bolsistas e professores supervisores do Pibid também é extremamente importante no processo de construção dos saberes experienciais por três motivos principais: primeiro, devido ao tempo de serviço que os supervisores têm com o ensino regular; segundo, devido à convivência com os outros indivíduos que compõem o espaço escolar e como essa relação contribui para os trabalhos na escola e terceiro, devido à própria relação dos supervisores com os estudantes e o cuidado que eles têm pelo processo de ensino e aprendizagem (CARMO, 2015). Os entrevistados também indicaram a importância do professor supervisor na formação inicial deles, como observado nos trechos das falas a seguir:

A professora que me orientava no Pibid tinha muito a visão do lúdico, então ela incentivava muito para a gente criar jogos ou aulas práticas, então eu tive essa oportunidade de estar desenvolvendo muitas atividades nesse lado e foi muito bom para minha formação profissional porque hoje eu não tenho dificuldade em criar essas atividades (EGRESSO 8).

No Pibid, eu tinha uma professora magnífica (supervisora) atuando na escola pública em Alegre e a gente aprende muito também observando [...] observando o que ela fazia eu pude aprender e obter conhecimentos da minha área de atuação hoje (EGRESSO 19). 
Ter um supervisor excepcional me acompanhando, além do suporte de uma universidade e depois ser o professor, te faz ter certeza que você está fazendo o correto, porque você se baseia na posição do supervisor e dos professores da universidade, então não tem como você sair do Pibid sem saber que é aquilo que você quer de fato (EGRESSO 26).

No contexto do Pibid, o professor supervisor participa como coformador dos futuros professores, ou seja, ele deve ser "capaz de dividir com os outros seus saberes profissionais e suas reflexões frente às atitudes tomadas [...], tendo a capacidade de acolher e de se dispor a atender e auxiliar" (AZEVEDO, 2009, p. 81). Essa troca de conhecimentos entre futuros professores e os professores do ensino básico é essencial para a construção e o desenvolvimento de saberes experienciais, pois o supervisor orienta os futuros professores para que "mobilizem conhecimentos, habilidades e atitudes específicas, no campo de atuação docente" (AZEVEDO, 2009, p. 82). O contato frequente com o ambiente escolar e a relação criada com o professor supervisor permitem que os futuros professores construam perspectivas mais coerentes com a carreira docente, bem como reflitam sobre as responsabilidades sociais que a carreira docente tem e como as escolhas realizadas podem afetar a vida do estudante e sociedade de forma geral (CARMO, 2015).

Isso posto, a partir das análises das entrevistas, pode-se afirmar que os futuros professores, ao participarem do Pibid e vivenciarem o espaço escolar, iniciam o processo de construção de saberes experienciais necessários à prática docente. Estes saberes são constatados, por exemplo, quando os entrevistados fazem a ressignificação do espaço escolar compreendendo-o como um ambiente organizado, com suas regras e limitações, ou seja, espaço profissional.

Também puderam, por outro lado, compreender que essa organização pode enfrentar situações inesperadas que lhes exigirão a reorganização e replanejamento de atividades. Além disso, compreendem que a relação entre professor e aluno está diretamente ligada ao processo de ensino e aprendizagem, por isso torna-se necessário que essa relação seja positiva e saudável. Por fim, a relação com os professores supervisores do Pibid e demais profissionais docentes que atuam como coformadores torna-se extremamente importante na formação inicial dos futuros professores, pois permite-lhes a reflexão sobre a carreira docente e sua importância na sociedade.

\section{CONSIDERAÇÕES FINAIS}

Acredita-se que o encontro com o ambiente escolar, no contexto das experiências proporcionadas pelo Pibid, possibilita que futuros professores iniciem o processo de construção de um conjunto de saberes essenciais relacionados à prática docente. Dessa forma, as experiências proporcionadas aos egressos do subprojeto "Pibid Biologia-Alegre" foram analisadas, verificando a construção dos principais saberes docentes necessários para a prática, constatados na própria atuação destes egressos como docentes. Sob esta ótica, as análises realizadas indicaram que o Pibid se caracteriza como um espaço formativo para futuros profissionais docentes, proporcionando-lhes o início da construção de saberes ao vivenciarem as particularidades do espaço escolar. 
Pode-se afirmar que programas e iniciativas de incentivo e valorização docente, como o Pibid, reduzem o distanciamento existente entre a teoria e a prática dos cursos de formação docente, permitindo que os futuros professores compreendam que, no exercício da carreira, tais elementos precisam se relacionar e são dependentes um do outro em muitos momentos da prática docente. Sendo assim, o Pibid contribui para experiências formativas que poderiam ocorrer somente após o processo de formação inicial, ou seja, no exercício profissional, tendo como principal contribuição o contato prévio proporcionado aos futuros professores no ambiente escolar, possibilitando-lhes conhecer a dinâmica da profissão na própria prática e preparando-os para atuar profissionalmente sem ainda estarem com o compromisso formal da docência. Como destacado nas próprias narrativas dos egressos participantes desta pesquisa, o Pibid possibilitou-lhes, em vários momentos da atuação profissional, experiências significativas advindas da construção dos principais saberes docentes possibilitados pelas atividades no contexto do Pibid, ou seja, pode-se afirmar que o Programa se configura, também, como oportunidade de formação continuada, pois os professores que já foram bolsistas do Pibid na própria prática fazem relações entre as atividades desenvolvidas como bolsistas e a atuação como profissionais.

Por fim, destaca-se nesta pesquisa que as experiências do Pibid possibilitam, aos futuros professores e professores em exercício, uma formação coletiva, na qual indivíduos com distintas experiências formativas têm a oportunidade de elaborarem, executarem e refletirem coletivamente sobre as atividades que serão desenvolvidas no espaço escolar e para o espaço escolar. Como consequência, a formação docente tende a superar, cada vez mais, os desafios que acompanham a temática em uma perspectiva centrada no potencial social que o papel do profissional docente possui na sociedade atual, permitindo a sua análise a partir da prática e compreendendo os diferentes saberes que constituem a profissão.

Vale destacar a importância de se compreender o espaço escolar como local de formação, pois possui uma organização e relações pessoais e profissionais que são características da profissão docente. Nessa perspectiva, cabe refletir sobre até que ponto é possível existir formação docente que dissocie a formação inicial da escola de Educação Básica, pois existem saberes que só são possíveis de serem construídos por intermédio dessa correlação e que são importantes para o desenvolvimento da prática docente, além de a escola possuir conhecimentos específicos sobre a profissão docente que só serão descobertos e/ou desenvolvidos dentro deste ambiente.

\section{REFERÊNCIAS}

AMARAL, Gabriel da Silva; BISPO, Anagessica Santana; RODRIGUES, Luciana Lima; SANTOS, Ivete Maria dos; MASSENA, Prestes; FILHO, José de Guzzi. Pibid/Química Uesc: ensinando concentração através de uma Situação de Estudo no curso técnico de biotecnologia. In: ENCONTRO NACIONAL DE PESQUISA EM EDUCAÇÃO EM CIÊNCIAS (ENPEC), 9., 2013. Águas de Lindoia, SP. Atas [...]. Águas de Lindóia, SP: Enpec, 2013. p. 1-8.

AZEVEDO, Maria Antônia Ramos de. Os saberes de orientação dos professores formadores: desafios para ações tutoriais emancipatórias. 2009. Tese (Doutorado em Educação) - Universidade de São Paulo, Faculdade de Educação, São Paulo, 2009. 
BACCON, Ana Lúcia Pereira; ARRUDA, Sérgio de Mello. Os saberes docentes na formação inicial dos professores de física: elaborando sentidos para o Estágio Supervisionado. Ciência \& Educação, Bauru, v. 16, n. 3, p. 507-524, 2010.

BARDIN, Laurence. Análise de conteúdo. São Paulo: Edições 70, 2016.

BELOTTI, Salua Helena Abdalla; FARIA, Moacir Alves de. Relação professor/aluno. Revista Eletrônica Saberes da Educação, v. 1, n. 1, p. 1-12, 2010.

BIZZO, Nelio. Ciências: Fácil ou Difícil? São Paulo: Editora Ática, 2002.

CAPES. Fundação Coordenação de Aperfeiçoamento de Pessoal de Nível Superior. Pibid - Programa Institucional de Bolsa de Iniciação à Docência. 2021. Disponível em: https://www.gov.br/capes/pt-br/acesso-a-informacao/acoes-e-programas/educacao-basica/pibid. Acesso em: 23 jun. 2021.

CARMO, Hadassa Marques Santana. As contribuições dos subprojetos do PIBID-UESC para a constituição dos saberes docentes na formação inicial de professores de Ciências. 2015. Dissertação (Mestrado em Educação em Ciências) - Universidade Estadual de Santa Cruz, Ilhéus, 2015.

CARVALHO, Anna Maria Pessoa de; GIL-PÉREZ, Daniel. A ruptura com visões simplistas sobre o ensino de ciências. In: CARVALHO, Anna Maria Pessoa de; GIL-PÉREZ, Daniel. PEC Formação de Professores de Ciências: tendências e inovação. São Paulo: Cortez, 2001. p. 13-63.

CAVALCANTE, Maria Mikaele da Silva; FARIAS, Isabel Maria Sabino de. Permanecer na docência: o que revelam professores iniciantes egressos do Pibid? Revista Educação em Questão, Natal, v. 58, n. 58, p. 1-24, 2020.

CHAPANI, Daisi Teresinha; LUZ, Carla Patrícia Novais. Programa Institucional de Bolsas de Iniciação à Docência: avaliação de resultados. Revista de Iniciação à Docência, v. 3, n. 1, p. 4-21, 2018.

CORREIA, Gerson dos Santos. Estudos dos conhecimentos evidenciados por alunos dos cursos de licenciatura em Matemática e Física participantes do PIBID-PUC/SP. 2012. Dissertação (Mestrado em Educação Matemática) - Pontifícia Universidade Católica de São Paulo, São Paulo, 2012.

FILHO, José Camilo dos Santos; DIAS, Carmem Lúcia. Profissão acadêmica e scholarship da docência: novo olhar sobre as múltiplas funções do professor universitário. Revista da Avaliação da Educação Superior, Campinas, v. 21, n. 3, p. 837-857, 2016.

FREITAS, Helena Costa Lopes de. Formação de professores no Brasil: 10 anos de embate entre projetos de formação. Educação \& Sociedade, Campinas, v. 23, n. 80, p. 136-167, 2002.

GATTI, Bernardete Angelina. A atratividade da carreira docente no Brasil. In: FUNDAÇÃO VICTOR CIVITA. Estudos \& Pesquisas Educacionais. São Paulo: Fundação Victor Civita, 2010. p. 1-82.

GAUTHIER, Clermont. Por uma teoria da pedagogia: pesquisas contemporâneas sobre o saber docente. 3. ed. Ijuí: Editora Unijuí, 2013.

GODOY, Arilda Schmidt. Pesquisa qualitativa: tipos fundamentais. Revista de Administração de Empresas, São Paulo, v. 35, n. 3, p. 65-71, 1995.

MACENO, Nicole Glock; GUIMARÃES, Orliney Maciel. O Programa Institucional de Bolsas de Iniciação à Docência e o desafio de ressignificar a docência. Contexto \& Educação, ljuí: Editora Unijuí, n. 93, p. 108137, 2014.

MARTINS, Maria Márcia Melo de. Saberes pedagógicos e o desenvolvimento de metodologias de ensino de Biologia: o PIBID como elemento de construção. 2013. Dissertação (Mestrado Profissional em Ensino de Ciências e Matemática) - Universidade Federal do Ceará, Fortaleza, CE, 2013.

MINISTÉRIO DA EDUCAÇÃO. Seleção pública de propostas de projetos de iniciação à docência voltados ao Programa Institucional de Iniciação à Docência - PIBID. Brasília, 2007. Disponível em: https://www.gov. br/capes/pt-br/centrais-de-conteudo/edital-pibid-pdf. Acesso em: 21 ago. 2019.

NASCIMENTO, Ivany Pinto; RODRIGUES, Sônia Eli Cabral. Representações sociais sobre a permanência na docência: O que dizem docentes do Ensino Fundamental? Educação e Pesquisa, São Paulo, v. 44, p. 1-16, 2018.

NEITZEL, Adair de Aguiar; FERREIRA, Valéria Silva; COSTA, Denise. Os impactos do Pibid nas Licenciaturas e na Educação Básica. Conjectura: Filosofia e Educação, Caxias do Sul, v. 18, n. especial, p. 98-121, 2013. NÓVOA, António. Professores: imagens do futuro presente. Lisboa: Educa, 2009.

PIMENTA, Selma Garrido. Formação de professores: identidade e saberes da docência. In: PIMENTA, Selma Garrido. Saberes pedagógicos e atividade docente. 8. ed. São Paulo: Cortez, 2012. p. 15-38. 
RIBEIRO, Victoria Maria Brant. A construção do conhecimento, o currículo e a escola básica. Revista Em Aberto, Brasília, n. 58, p. 67-72, 1993.

ROSA, Débora Lázara; MENDES, Ana Néry Furlan; LOCATELLI, Andrea Brandão. A sistematização dos saberes docentes em suas relações com a formação inicial de professores de Química. Contexto \& Educação, ljuí: Editora Unijuí, n. 105, p. 68-94, 2018.

SAVIANI, Dermeval. Formação de professores no Brasil: dilemas e perspectivas. Poíesis Pedagógica, v. 9, n. 1, p. 7-19, 2011.

SAVIANI, Dermeval. Os saberes implicados na formação do educador. In: BICUDO, Maria Aparecida; SILVA JUNIOR, Celestino Alves. Formação do educador: dever do Estado, tarefa da Universidade. São Paulo: Unesp, 1996. p. 39-50.

SHULMAN, Lee. Those who understand: Knowledge growth in teaching. Educational Research, v. 15, n. 2, p. 4-14, 1986.

TARDIF, Maurice. Saberes docentes e formação profissional. Petrópolis: Vozes, 2012.

TARDIF, Maurice; LESSARD, Claude. O trabalho docente: elementos para uma teoria da docência como profissão de interações humanas. 9. ed. Petrópolis: Vozes, 2014.

TEXEIRA JÚNIOR, José Gonçalves. Contribuições do Pibid para a formação de professores de Química. 2014. Tese (Doutorado em Química) - Universidade Federal de Uberlândia, Instituto de Química, Uberlândia, MG, 2014. 